\title{
Study on the Current Situation and Improvement Countermeasures of Medical Assistance in Chongqing
}

\author{
Wanqian Peng1, Yanzheng Dan², Meifu Duan², Zhengming Zhang², Dan Liu ${ }^{*}$, \\ Bin Zhang1, Xinyi Chen ${ }^{1}$ \\ ${ }^{1}$ Co-innovation Center for Predication and Management of Social Risks in Health Field, Research Center for Medical \\ Science and Social Development, Public Health and Management School, Chongqing Medical University, Chongqing, China \\ ${ }^{2}$ Chongqing Healthcare Security Administration, Chongqing, China \\ Email: *cat37056205@163.com
}

How to cite this paper: Peng, W. Q., Dan, Y. Z., Duan, M. F., Zhang, Z. M., Liu, D., Zhang, B., \& Chen, X. Y. (2021). Study on the Current Situation and Improvement Countermeasures of Medical Assistance in Chongqing. Advances in Applied Sociology, 11, 471-481.

https://doi.org/10.4236/aasoci.2021.1110041

Received: September 10, 2021

Accepted: October 23, 2021

Published: October 26, 2021

Copyright $\odot 2021$ by author(s) and Scientific Research Publishing Inc. This work is licensed under the Creative Commons Attribution International License (CC BY 4.0).

http://creativecommons.org/licenses/by/4.0/

\begin{abstract}
In this study, a comprehensive survey of medical assistance in Chongqing was conducted by literature review, group interview and questionnaires, and some prominent problems were found, including imperfect fund-raising mechanisms, complex medical assistance procedures, as well as inadequate propaganda and understanding of medical assistance policies. It is thereby proposed that the government shall further improve the financing mechanism of medical assistance funds, simplify the medical assistance procedures, and increase the publicity of medical assistance policies. Our study is expected to provide the governments with a decision-making reference when formulating and improving medical assistance policies.
\end{abstract}

\section{Keywords}

Medical Assistance, Difficulty, Reform Strategy

\section{Introduction}

Healthcare security is a major institutional arrangement to ease the public medical burden, improve the people's livelihood and welfare, and maintain social harmony and stability. Medical assistance is a basic institutional arrangement to guarantee the basic healthcare rights of people with economic difficulties, and a foundational institution in the healthcare security system, which embodies the deep concern of the party and the state for the medical problems of the people in difficulties as well as the great importance it attaches to the cause of medical assis- 
tance. The Opinions on Deepening the Reform of the Medical Security System by the Central Committee of the Communist Party of China and the State Council (Yu, 2020; Lou, 2020) clearly specifies "comprehensively establish a healthcare security institutional system with basic medical insurance as main body and medical assistance as foundational support, and combining the co-development of supplementary medical insurance, commercial health insurance, charitable donation, and mutual medical assistance by 2030 ". In the recent years, the governments have continuously deepened the medical system reform, perfected the healthcare security mechanism, and increased the healthcare security input. According to 2019 Statistical Bulletin on the Development of Healthcare Security Services published by the National Healthcare Security Administration, the subsidy fund for medical assistance from the central financial input was 24.5 billion yuan in 2019, of which 4 billion yuan was specifically designated for supporting the severely impoverished areas to improve the healthcare security level of impoverished population. The abovementioned macroscopic background creates a historical development opportunity and a working space for the medical assistance system. However, there are many faults and disputes in respect of the current development situation of medical assistance as a foundational project of healthcare security, and medical assistance problems also attract great concerns from the society and academic circles (Zhang et al., 2019).

Through a review on the studies of medical assistance completed by domestic scholars, it is seen that as Chinese medical assistance system was formally implemented later, there are some shortcomings for medical assistance researches in China, primarily manifested as the following three aspects: Firstly, there are more studies of countermeasures but fewer fundamental studies. The current evaluation and analysis of Chinese medical assistance system usually focus on the studies of countermeasures for the existing issues in the practice, and the researches on basic theories, explorations of laws, and summarizations of relevant theories for the system are obviously insufficient (Suo \& Feng, 2014; Xiao \& Li, 2012). Secondly, there are more local studies but fewer integral studies. Most current studies of medical assistance in China relate the summarizations of special laws for a certain medical assistance project, but there are rare achievements involving the realizations of a complete social security system and from the comprehensive and systematic studies (Zhang et al., 2019; Chen, 2011; Sun \& Qin, 2014). Thirdly, a significant imbalance is observed in the studies of overseas medical assistance systems, specifically the medical assistance systems in European and American developed countries have been more studied, while those in the developing countries have been less investigated (Heeju, 2017).

In Chongqing, as a unique municipality in Western China with a pattern of "the city leads its rural areas", there is a medical assistance system under insufficient development for various reasons. The relevant problems include scattered medical assistance funds, complex medical assistance application procedures, a timeconsuming approval process, long-time restrictions from the management system, and no organic connection with the basic medical insurance program and 
critical illness insurance program, which hinders the foundational security function and seriously impedes the sustainable development of medical assistance system in Chongqing. Therefore, conducting a study focusing on medical assistance policies in Chongqing is necessary to explore the comprehensive establishment of Chongqing-characterized medical assistance system.

\section{Materials and Methods}

\subsection{Source of Materials}

In 2020, 6 districts/counties in Chongqing were selected as samples by multi-phase stratified sampling. By combining the actual situations of the above sample areas, 400 medical assistance beneficiaries were surveyed with questionnaires, and about 50 managers were investigated in a way of group interview.

\subsection{Study Methods}

\subsubsection{Literature Review}

The foundation for the analysis of current situation and the development of questionnaires in this study was provided by searching the literature, documents, almanacs and other data in the literature databases (including CNKI, Wanfang Data, VIP Database), governmental websites, and Google search engine.

\subsubsection{Group Interview}

Totally 50 medical assistance managers of local medical insurance agencies and operators of medical institutions were selected for group interview to mainly understand their recognition, attitude, comments and suggestions to the existing medical assistance system.

\subsubsection{Questionnaires}

Totally 400 medical assistance beneficiaries were chosen in the sample areas. The questionnaires mainly related the behaviors, attitude and recognition of beneficiaries against medical assistance.

\subsubsection{Statistical Analysis}

The basic data of medical assistance in Chongqing and some qualitative data collected by interviews in sample areas were mainly analyzed by descriptive statistics, and the quantitative data were entered into Excel Database and then statistically analyzed with SPSS 16.0.

\section{Analysis of Results}

\subsection{Social Demographic Characteristics of Medical Assistance Objects in Chongqing}

In 400 medical assistance objects surveyed, there were 230 (57.5\%) males and 170 $(42.5 \%)$ females. In respect of education, there were $241(60.3 \%)$ cases of $\leq$ primary school (dominantly), 97 (24.2\%) cases of junior high school, 26 (6.5\%) cases of secondary vocational school and senior high school, and 36 (9\%) cases of $\geq$ three- 
year college. The average annual income was 0 - 6000 yuan in $263(65.7 \%)$ cases, $6000-12,000$ yuan in $70(17.5 \%)$ cases, and $\geq 12,000$ yuan in $77(16.8 \%)$ cases. The number of medical assistance objects living in rural areas, urban areas, and rural-urban fringe areas \& other areas was 260 (65\%), 50 (12.5\%), and $90(22.5 \%)$, respectively (see Table 1).

\subsection{Overview of Medical Assistance in Chongqing}

As compared with 2018, Chongqing Healthcare Security Administration raised totally 1.806 billion yuan for medical assistance funds in 2019, with a growth of 48.33\%; 492 million yuan, 1.152 billion yuan and 216 million yuan was separately from Central Finance (with a decline of 20.65\%), Chongqing Finance (with a growth of $80 \%$ ) and the self-financing or interest income of district/county finance. There were 1,610,900 medical assistance objects enjoying assisted insurance in Chongqing (with a growth of 5.19\%), including 182,800 (11.35\%) cases of relief and support living in dire poverty, 854,300 (53.03\%) cases of urban-rural minimum living standard allowance, and 573,800 (35.62\%) cases under other difficulties. The total fund for assisted insurance by medical assistance in the whole city was 341 million yuan with a growth of $26.30 \%$, including 42 million yuan for medical assistance objects with relief and support living in dire poverty, 192 million yuan for those with urban-rural minimum living standard allowance, and 107 million yuan for those under other difficulties. The annually registered impoverished population with medical assistance of 222 million yuan from district/county finance was $1,663,900$.

Table 1. Social demographic characteristics of medical assistance objects in Chongqing.

\begin{tabular}{|c|c|c|c|}
\hline & & $\mathrm{N}$ & $\%$ \\
\hline \multirow{3}{*}{ Sex } & Male & 230 & 57.5 \\
\hline & & & \\
\hline & Female & 170 & 42.5 \\
\hline \multirow{4}{*}{ Education } & $\leq$ Primary school & 241 & 60.3 \\
\hline & Junior high school & 97 & 24.2 \\
\hline & Secondary vocational school and senior high school & 26 & 6.5 \\
\hline & $\geq$ Three-year college & 36 & 9.0 \\
\hline \multirow{4}{*}{$\begin{array}{l}\text { Average annual } \\
\text { income }\end{array}$} & $0-6000$ yuan & 263 & 65.7 \\
\hline & $6000-12,000$ yuan & 70 & 17.5 \\
\hline & $12,000-24,000$ yuan & 35 & 8.7 \\
\hline & $\geq 24,000$ & 42 & 8.1 \\
\hline \multirow{4}{*}{ Habitation type } & Urban area & 50 & 12.5 \\
\hline & Rural-urban fringe area & 49 & 12.2 \\
\hline & Township center & 41 & 10.3 \\
\hline & Rural area & 260 & 65.0 \\
\hline
\end{tabular}




\subsection{Imperfect Financing Mechanism of Medical Assistance Funds}

At present, the medical assistance funds in various districts/counties of Chongqing are mainly from Central Finance and Chongqing Finance, with great dependence on the funding of senior governments. For example, Central Finance and Chongqing Finance arranged medical assistance funds of totally 1.256 billion yuan (616 million yuan and 640 million yuan, respectively) in 2018. Nationally, the central financial input was 24.5 billion yuan in 2019 , accounting for $48.79 \%$ of the annual medical assistance expenditure; in 2017, the annual medical assistance expenditure was 37.62 billion yuan, which is relatively low in respect of total amount; in 2018, the total expenditure of basic medical insurance funds was 1760.765 billion yuan, of which the total medical assistance expenditure only accounted for 2.14\% (Wang, 2019a). The total amount of medical assistance funds is insufficient due to narrow fund-raising channels and weak social financing intensity (Xiong et al., 2019). The concerned principal also pointed out in the interview that the major sources of medical assistance funds were Central Finance and Chongqing Finance, and the financial gaps were filled by district/county finance after these funds were allocated to various districts/counties, thus the funding source was limited. With the continuous expansion of medical assistance scope, a gradual increase of assisted diseases, and a progressive elevation in the medical assistance proportion, the medical assistance demand of people with economic difficulties is hard to be met effectively.

\subsection{Complex Medical Assistance Procedures}

As the staffs in civil affairs departments who previously took charge of medical assistance work have not been transferred with their duties and responsibilities, the new staffs responsible for such work after reform are not familiar with business policies and operation procedures. Besides, the medical assistance policies and operation procedures in various districts/counties are not consistent. The concerned principal of the healthcare security administration stated in an informal discussion that the responsibilities of grass-root units were not specified. Before institutional reform and responsibility transfer, the approval, management and allowance of medical assistance objects were operated by town/street/community offices, and the assisted insurance was the duty of social security administration offices. After separation from the human resources and social security bureaus, the healthcare security administrations have no governed grass-root execution units. After taking over the medical assistance work, various townships demonstrate different execution practices, the community offices and the social security administration offices may both be in charge of medical assistance, which results in poor communication and confused responsibilities of medical assistance business operation departments. In the opinion of relevant departments, the healthcare security administrations are the competent departments of medical assistance and shall be responsible for all medical assistance affairs. As a result, the communication and coordination during working are very difficult, and there are such 
phenomena as work conflicts and prevarications; a few of departments or units fail to timely, effectively and accurately send the information data of medical assistance objects to the healthcare security administrations, thus causing no in-time medical assistance of partial objects and even no medical assistance which should be provided. A study (Wang, 2019b) showed that the capital expenditure of medical assistance was in a small scale (only over 30 billion yuan), as compared with the annual expenditure of basic medical insurance (1700 billion yuan). The unit cost is very high for competent departments to separately establish an information network for application, approval, settlement and supervision. Therefore, the management and operation services of medical assistance in the majority of areas are still completed manually, which has such shortcomings as complex operation procedures, a long operation time, and a high error rate (Song, 2013).

For the question "which problems are there in the implementation of medical assistance policies (multiple options)", 37.2\% respondents chose complex medical assistance procedures and suggested simplifying these procedures. As shown by the analysis of 400 medical assistance objects in Table 2, 140 (35\%) cases were low and very low in respect of the understanding degree of medical assistance procedures. This indicated that about $1 / 3$ medical assistance objects lacked the recognition of medical assistance procedures, maybe because these procedures were complex and there were no pathways and channels for medical assistance objects to understand them. Thus, the publicity and education of medical assistance procedures and policies for medical assistance objects need to be strengthened via some formal channels (Zhen, 2019), so as to better respect and guarantee the public health and life rights.

\subsection{Inadequate Propaganda and Understanding of Medical Assistance Policies}

Currently a part of people with economic difficulties are still not insured, and the temporary insurance completed when critical diseases occur will lead to a result that the medical costs during the long-time elimination period cannot be included into the medical insurance reimbursement, thus failing to achieve the

Table 2. Understanding degree of medical assistance procedures by medical assistance objects in Chongqing.

\begin{tabular}{cccc}
\hline & & $\mathrm{N}$ & $\%$ \\
\hline & Very high & 40 & 10.0 \\
& High & 85 & 21.2 \\
$\begin{array}{c}\text { Understanding degree of medical } \\
\text { assistance procedures }\end{array}$ & Moderate & 135 & 33.8 \\
& Low & 119 & 29.7 \\
& Very low & 21 & 5.3 \\
& Total & 400 & 100.0 \\
\hline
\end{tabular}


medical assistance purpose. The public have no enough understanding to critical illness insurance in the medical insurance program, medical assistance, civil temporary assistance, and charitable assistance policies. Due to the misleading by the propaganda of medical institutions, the common population excluding medical assistance objects often, with a biased attitude, consider critical illness insurance in the medical insurance program, medical assistance, civil temporary assistance, and charitable assistance as "critical illness assistance" policies after suffering from critical and severe diseases, and wrongly think they can enjoy "critical illness assistance"; eventually, they are undoubtedly disappointed with beautiful expectations.

According to the data about the understanding degree of medical assistance policies in Table 3, only $11.0 \%$ of 400 medical assistance objects were very high, while $28.8 \%$ were low and very low. Therefore, the social popularity of medical assistance is to be increased, and the propaganda depth of medical assistance policies needs to be enhanced.

As revealed by Figure 1 showing the pathways that the medical assistance objects understood medical assistance policies, $16.8 \%$ knew such policies from relatives, friends, or other residents, causing deviated information comprehension; $6.6 \%$ did not know these policies. The concerned principals of hospitals pointed out in the interview that the patients with medical assistance were not clearly aware of their allowances, their actual benefits were far away from their reimbursement expectations, and they were unsatisfied about their enjoyed assistance and complained of low insurance reimbursement and medical assistance for their critical illness.

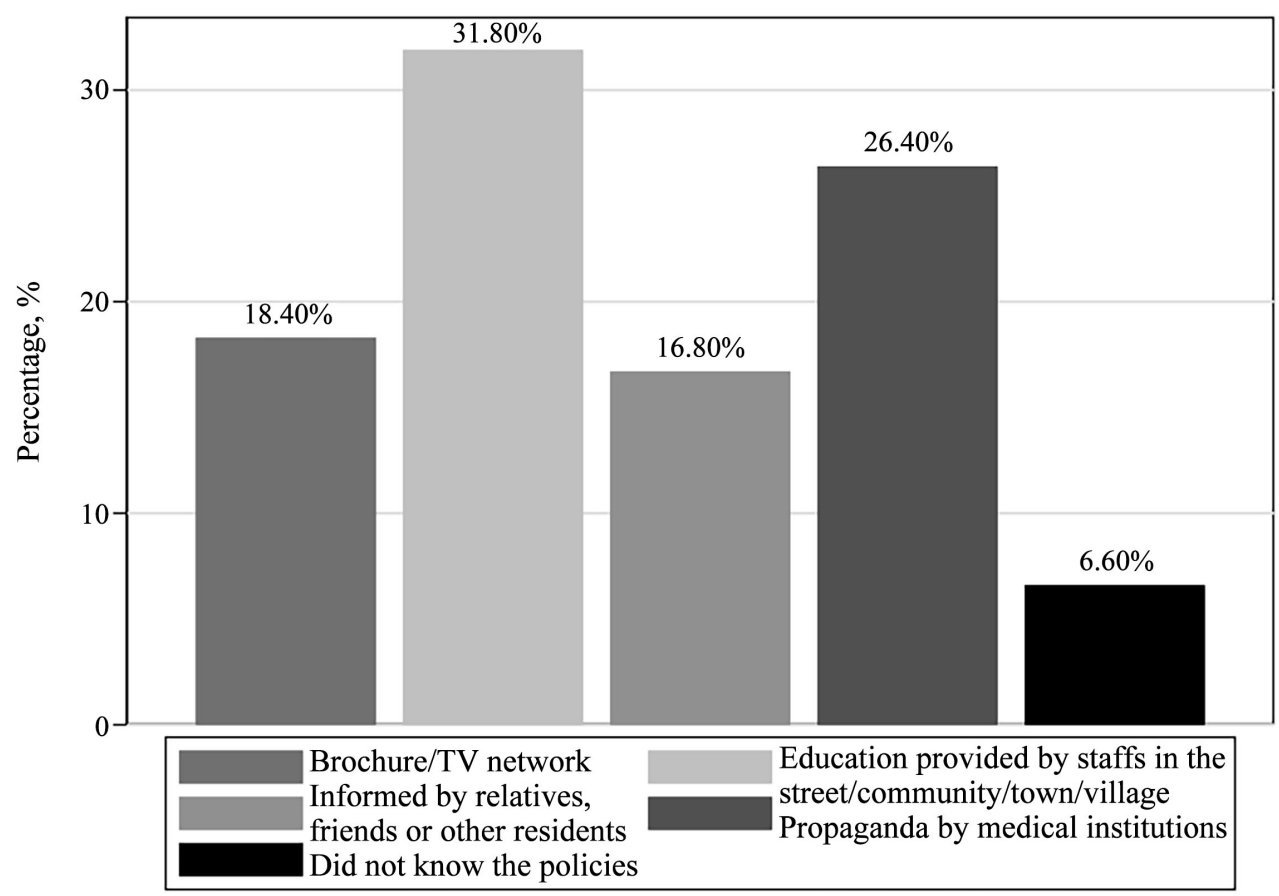

Figure 1. Pathways that the medical assistance objects understood medical assistance policies. 
Table 3. Understanding degree of medical assistance policies by medical assistance objects in Chongqing.

\begin{tabular}{cccc}
\hline & & $\mathrm{N}$ & $\%$ \\
\hline & Very high & 44 & 11.0 \\
Understanding & High & 135 & 33.7 \\
degree of medical & Moderate & 106 & 26.5 \\
assistance policies & Low & 100 & 25.0 \\
& Very low & 15 & 3.8 \\
& Total & 400 & 100.0 \\
\hline
\end{tabular}

\section{Suggestions}

\subsection{Improving the Financing Mechanism of Medical Assistance Funds}

Our suggestions are as follows: 1) integrating the scattered medical assistance responsibilities of various departments, and establishing a stable fund-raising mechanism; 2) expanding the medical assistance financing channels, and getting rid of single patterns of completely depending on the financial departments at various levels (Wei, 2015); 3) combining the medical assistance undertaking mechanism with charitable assistance and social donations, centralizing all funds of medical assistance programs, making sure of medical assistance fund sources, and building a stable and sustainable financing mechanism. As pointed out by the concerned principal of XX District Healthcare Security Administration in Chongqing, the district finance paid over 5 million yuan and Chongqing Finance allocated over 8 million yuan for medical assistance in 2019; in 2020, the municipal subsidy was increased by 4 million yuan. The study (Xin et al., 2019) suggested that the channels for the fund sources of medical assistance should be diversified. It is thereby suggested to establish a financing mechanism dominated by governmental investment, make full use of social strengths for the multi-party raising of medical assistance funds, institutionalize and standardize such funding ways as the participation of non-governmental organizations (e.g., charities), social donations, and the release of welfare lotteries, and improve the utilization efficiency of medical assistance funds. Besides, it is also suggested to timely issue and implements the policies encouraging social donations (e.g., preferential policies that the donators can enjoy tax credits), thus creating some conditions for effectively expanding the financing channels and making social donations become an important supplement of Chinese medical assistance funds. In 2019, the Central Finance arranged the expenditure of lottery public welfare funds being 71.758 billion yuan and that of medical assistance being 1.8 billion yuan, which was organized and implemented by the National Healthcare Security Administration mainly to assist the impoverished population for the participation in urban-rural resident medical insurance and provide allowances for their out-of-pocket basic medical costs. 


\subsection{Simplifying the Medical Assistance Procedures}

Some suggestions are described below: 1) standardizing the medical assistance operation procedures at the provincial level, enhancing the business guidance, and carrying out the comprehensive and systematic training of medical assistance business; 2) dispersing the business section into various existing business departments, and specifying the undertaking departments of various businesses in the state, cities, districts, towns, and streets; 3) determining the duties and responsibilities to benefit the successful work implementation; 4) formulating a simplified standard medical assistance workflow, gradually cancelling and standardizing the unreasonable operation procedures, and assuring the non-differential implementation of medical assistance work in various areas. The concerned principal of XX Healthcare Security Administration proposed in the interview that although the healthcare security administrations were separated from the human resources and social security bureaus, healthcare security still belonged to social security, so the grass-root healthcare security responsibilities should be still undertaken by social security offices. It was suggested in some study (Sun, 2018) to include the qualification authentication of medical assistance into the medical insurance participation system and optimize the application, review, approval and other links of medical assistance using this system, thus reducing the application procedures and improving the accuracy of qualification authentication. In addition, we also suggest marking the demographic information of medical assistance in the medical insurance participation system and settlement system, so that the medical costs complying with the medical assistance conditions can be directly settled via the medical insurance settlement system once occurring.

\subsection{Increasing the Publicity of Medical Assistance Policies}

There are several suggestions: 1) propagating the basic medical insurance, critical illness insurance and medical assistance policies in an all-round and multi-level way by the propaganda month and community/hospital access of medical insurance policies, emphasizing the importance of medical insurance participation, and realizing the awareness of each family and each person; 2) enhancing the propaganda guidance of healthcare security policies, and reasonably determining the institutional scopes of basic medical insurance, critical illness insurance and medical assistance; 3 ) making sure that the public fully understand the policies, correctly comprehend the reimbursement and assistance standards and beneficiaries of medical insurance policies and medical assistance policies, and correctly distinguish the general benefiting of basic medical insurance \& critical illness insurance and the specificity of medical assistance, thus avoiding the "assistance $=$ welfare" wrong recognition of partial people and practically improving the awareness and satisfaction of healthcare security policies. According to the suggestions in some study (Suo \& Feng, 2014), the medical insurance operation agencies in the medical insurance participation areas shall strengthen the training of business operators, so that these operators can real-time know a variety of 
policy information and provide the detailed interpretation of various policies and medical care procedures for insured persons when handling the medical insurance registration and filing. Besides, it is also suggested to extensively propagate the policies and workflow of medical assistance in-time settlement and the responsibilities of designated medical institutions by fully using new media, convenience service windows of grass-root governments, park plazas, medical institutions, village/community bulletin boards, and other public places, so that a wide range of people with economic difficulties fully understand the medical assistance policies.

\section{Conclusion}

At present, Chongqing medical assistance system has three shortages below: 1) imperfect fund-raising mechanism of medical assistance; 2) complex medical assistance procedures; and 3) inadequate propaganda and understanding of medical assistance policies. To comprehensively establish Chongqing-characterized medical assistance system, the following targeted solutions are thereby proposed in this study: 1) improving the financing mechanism of medical assistance funds; 2) simplifying the medical assistance procedures; and 3) increasing the publicity of medical assistance policies.

\section{Fund Project}

"Research on Chongqing Medical Assistance System Based on 'Holistic' Governance Perspective" project funded by Chongqing Municipal Education Commission in 2020, Grant Number: KJQN202000413; "Research on the Overall Construction Strategy of Chongqing Medical Assistance System from the Perspective of Strategic Process Management" project funded by Chongqing Science and Technology Bureau in 2021, Grant Number: cstc2021jsyj-zzysbAX0038; "Research on Perfecting Medical Assistance System in Chongqing" project funded by Chongqing Science and Technology Bureau in 2020, No. cstc2020jsyj-zdxwtA0014.

\section{Conflicts of Interest}

The authors declare no conflicts of interest regarding the publication of this paper.

\section{References}

Chen, X. C., \& Yao, L. (2011). Analysis on the Basic Situation of China's Medical Assistance Financing and Complement between 2005-2010. Medicine and Society, 24, 49-51.

Lou, X. (2020). Difficulties and Countermeasures in the Implementation of Medical Assistance. China Health Insurance, 29-31.

Heeju, S. (2017). Medicaid's Lasting Impressions: Population Health and Insurance at Birth. Social Science \& Medicine, 177, 205-212. https://doi.org/10.1016/j.socscimed.2017.01.043

Song, Y., Han, J.-J., \& Guo, H.-Y. (2013). Study on the Problems in Medical Assistance System and Its Countermeasures. Taxation and Economy, 46-49. 
Sun, J. (2018). Medical Assistance Develops in a More Flexible and Accurate Pattern. Chinese Health, 92-93.

Sun, J., \& Qin, Y. (2014). Study on the Assistance Effect and Horizontal Equity of Medical Assistance System. Chinese Health Economics, 33, 22-25.

Suo, L.-Y., \& Feng, P.-C. (2014). International Experiences in Medical Assistance System and Implications for China. Chinese Journal of Health Policy, 12-16.

Wang, C. Q. (2019a). The Medical Assistance System Is to Be Segmented. Health News, 2019-06-24

Wang, Z. (2019b). Medical Insurance and Medical Assistance: Theory, Reality and Policy. China Health Insurance, 15-18.

Wei, X. Z. (2015). Study on Urban and Rural Medical Assistance Financing Mechanisms in China. Health Economics Research, 42-45.

Xiao, Q., \& Xiang, L. (2012). Object Definition of Catastrophe Assistance in China. Chinese Health Economics, 31, 22-24.

Xin, Y. J., Jiang, J. N., Wang, X. F., Luo, F., \& Xiang, L. (2019). Analysis of Medical Assistance Fund Demand in Xiantao under Health Poverty Alleviation Policy City, Hubei Province. Medicine and Society, 32, 59-62.

Xiong, X.-C., Zhou, Y.-N., Cao, X.-L., He, S.-Y., Dai, R.-M., \& Luo, L. (2019). Current Situation, Challenges and Solutions of Medical Institution Supervision in China. Chinese Hospital Management, 39, 21-22.

Yu, B.-R. (2020). Design and Thinking of China's Medical Security System in the Next 5-10 Years-Interpretation of Opinions on Deepening the Reform of the Medical Security System by the Central Committee of the Communist Party of China and the State Council. Health Economics Research, 37, 3-7.

Zhang, C. J., Dong, K., Dong, Q. et al. (2019). Accurate Target Orientation of Medical Assistance for Rural Poor People and Discussion of Countermeasures. Medicine and Society, 32, 18-20.

Zhen, X. W. (2019). Problems and Solutions in Cross-Provincial Non-Local Medical Insurance Settlement. Management Scientist, 93-94. 